\title{
Genetic variants associated with angiotensin-converting enzyme inhibitor-induced cough: a genome-wide association study in a Swedish population
}

\begin{abstract}
Aim: We conducted a genome-wide association study on angiotensin-converting enzyme inhibitor-induced cough and used our dataset to replicate candidate genes identified in previous studies. Patients \& methods: A total of 124 patients and 1345 treated controls were genotyped using Illumina arrays. The genome-wide significance level was set to $p<5 \times 10^{-8}$. Results: We identified nearly genome-wide significant associations in CLASP1, PDE11A, KCNMB2, TGFA, SLC38A6 and MMP16. The strongest association was with rs62151109 in CLASP1 (odds ratio: 3.97; $p=9.44 \times 10^{-8}$ ). All top hits except two were located in intronic or noncoding DNA regions. None of the candidate genes were significantly associated in our study. Conclusion: Angiotensinconverting enzyme inhibitor-induced cough is potentially associated with genes that are independent of bradykinin pathways.
\end{abstract}

First draft submitted: 24 November 2016; Accepted for publication: 9 December 2016; Published online: 13 January 2017

Keywords: angiotensin converting enzyme inhibitors $\bullet$ bradykinin $\bullet$ cough $\bullet$ drug-related side effects and adverse reactions $\bullet$ enalapril $\bullet$ genome-wide association study $\bullet$ lisinopril - pharmacogenetics $\bullet$ quinapril $\bullet$ ramipril

Angiotensin-converting enzyme (ACE) inhibitors are commonly prescribed to manage hypertension and heart failure. Inhibition of ACE decreases the formation of the vasoconstrictor angiotensin II and reduces the metabolism of the vasodilator bradykinin, thereby contributing to lower blood pressure [1]. In 2015, 7\% of the Swedish population was prescribed an ACE inhibitor [2]. Although ACE inhibitors are considered relatively safe, a substantial number of patients (5-35\%) experience an adverse drug reaction (ADR) in the form of persistent dry cough that may lead to treatment discontinuation. Cough symptoms generally disappear within a month of drug withdrawal, but may remain longer in some patients [3]. Female sex, chronic obstructive pulmonary disease (COPD) and asthma are possible risk factors for ACE inhibitor-induced cough [4]. The effect of cigarette smoke is debated, as an increased risk of drug-induced cough has been reported for both smokers $[4,5]$ and nonsmokers [6]. Patients experiencing ACE inhib- itor-induced cough are generally changed to an angiotensin receptor blocker, which is less associated with this type of ADR [7].

The pathogenesis of ACE inhibitor-induced cough is believed to be associated with increased plasma levels of bradykinin, substance $\mathrm{P}$ and prostaglandins [6,8]. Candidate gene studies of these pathways have identified suspected causative SNPs in certain patients. The candidate genes include $B D K R B 2$ [9-12], $M M E$ [12], PTGER3 [12], NK2R (TACR2) [13] and $A C E[11,12]$. One study also reported an association with the blood group factor gene $A B O$ [11]. Overall,results from these candidate genes have been inconsistent across studies. A recent genome-wide association study (GWAS) in patients with ACE inhibitor-induced cough performed in a mixed ancestry American population [14] further identified associations with SNPs in the potassium channel gene KCNIP4. The strongest associations with KCNIP4 were in patients of European ancestry. We performed a GWAS on ACE inhibitor-induced cough in a genetically homogenous Swedish
Pär Hallberg', Matilda Persson', Tomas Axelsson², Marco Cavalli ${ }^{3}$, Pia Norling ${ }^{4}$, Hans-Erik Johansson ${ }^{5}$, Qun-Ying Yue ${ }^{6}$, Patrik KE Magnusson 7 , Claes Wadelius ${ }^{3}$, Niclas Eriksson ${ }^{8} \& \mathrm{Mia}$ Wadelius $*, 1$

'Department of Medical Sciences, Clinical Pharmacology \& Science for Life Laboratory, Uppsala University, Uppsala, Sweden

${ }^{2}$ Department of Medical Sciences, Molecular Medicine \& Science for Life Laboratory, Uppsala University, Uppsala, Sweden

${ }^{3}$ Department of Immunology, Genetics \& Pathology \& Science for Life Laboratory, Uppsala University, Sweden ${ }^{4}$ Sickla Health Centre, Nacka, Sweden ${ }^{5}$ Department of Public Health \& Caring Sciences/Geriatrics, Uppsala University, Uppsala, Sweden

${ }^{6}$ Medical Products Agency, Uppsala, Sweden

${ }^{7}$ Swedish Twin Registry, Department of Medical Epidemiology \& Biostatistics, Karolinska Institutet, Stockholm ${ }^{\circledR}$ Uppsala Clinical Research Center \& Department of Medical Sciences, Uppsala University, Uppsala, Sweden *Author for correspondence: mia.wadelius@medsci.uu.se

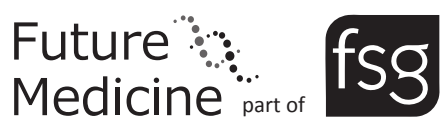


population, and used our dataset to replicate candidate genes identified in previous studies.

\section{Patients \& methods}

\section{Sample description}

Cases were recruited through SWEDEGENE [15], which is a biobank of ADRs run by Uppsala University in collaboration with the Swedish Medical Products Agency and Karolinska Institutet in Sweden. The majority of the cases were recruited from spontaneous ADR reports sent from healthcare professionals to the national drug regulatory authority. Clinical data (demographics, medical history, drug treatment history, laboratory data and ancestry) were collected through interviews using a standardized questionnaire, and by obtaining and reviewing medical records. All potential cases were evaluated by an investigator to ensure time relationship with an ACE inhibitor, and a positive dechallenge within 3 months following treatment discontinuation [16]. This resulted in 124 included cases, where the drug was plausably causative of cough symptoms. DNA was extracted from peripheral venous blood. Cases were genotyped using the Illumina HumanOmni2.5 array.

Treated controls were available from the Swedish Twin registry [17]. Twins who had collected at least two prescriptions of ACE inhibitors between 2005 and
2012 based on data from the National Prescribed Drug Register [2] were eligible. Only one twin from each pair was selected, resulting in a total of 1345 unrelated controls. A majority of the controls were of Swedish origin. Disease history was obtained from a subset of the treated controls $(\mathrm{n}=956)$. The International Classification of Diseases (ICD) diagnoses included in the study were hypertension (ICD-10: I10-I15), heart failure (ICD-10: I50), diabetes (ICD-10: E10-E14), COPD (ICD-10: J43), emphysema (ICD-10: J44) and asthma (ICD-10: J45). The controls had previously been genotyped using the Illumina HumanOmniExpress 700K BeadChip (Illumina, CA, USA).

\section{Power calculation}

When using all 124 cases and 1345 controls, the power to detect an odds ratio (OR) between 2 and 4 was $80 \%$ for variants with minor allele frequencies (MAFs) between 10 and 50\% (Supplementary Figure 1). The calculation was based on a genome-wide significance level of $\mathrm{p}<5 \times 10^{-8}$, an ADR prevalence of $10 \%$ and an additive genetic model [18].

\section{Genome-wide array data \& analyses}

We performed GWAS on 124 patients with ACE inhibitor-induced cough and 1345 treated controls. Cases

\begin{tabular}{|c|c|c|c|c|}
\hline Gene & Protein & Chromosome & Start position & End position \\
\hline$A B O$ & Histo-blood group $A B O$ system transferase & 9 & $136,125,788$ & $136,150,617$ \\
\hline$A C E$ & Angiotensin converting enzyme & 17 & $61,554,422$ & $61,599,205$ \\
\hline AGTR1 & Angiotensin II receptor, type 1 & 3 & $148,415,571$ & $148,460,795$ \\
\hline$B D K R B 1$ & Bradykinin receptor B1 & 14 & $96,722,161$ & $96,735,304$ \\
\hline$B D K R B 2$ & Bradykinin receptor $\mathrm{B} 2$ & 14 & $96,671,016$ & $96,710,666$ \\
\hline CPN1 & Carboxypeptidase N, polypeptide 1 & 10 & $101,801,950$ & $101,841,634$ \\
\hline CPN2 & Carboxypeptidase N, polypeptide 2 & 3 & $194,060,494$ & $194,072,057$ \\
\hline KCNIP4 & Potassium channel interacting protein 4 & 4 & $20,730,239$ & $21,950,422$ \\
\hline MCC & Mast cell chymase & 5 & $112,357,796$ & $112,824,527$ \\
\hline$M M E$ & Membrane metalloendopeptidase & 3 & $154,741,913$ & $154,901,497$ \\
\hline NOS1 & Nitric oxide synthase 1 & 12 & $117,645,947$ & $117,889,975$ \\
\hline PTGER1 & Prostaglandin E receptor 1 & 19 & $14,583,278$ & $14,586,174$ \\
\hline PTGER2 & Prostaglandin E receptor 2 & 14 & $52,781,023$ & $52,795,324$ \\
\hline PTGER3 & Prostaglandin E receptor 3 & 1 & $71,318,036$ & $71,513,491$ \\
\hline PTGER4 & Prostaglandin E receptor 4 & 5 & $40,679,600$ & $40,693,837$ \\
\hline PTGES & Prostaglandin E synthase & 9 & $132,500,610$ & $132,515,326$ \\
\hline PTGIR & Prostaglandin 12 receptor & 19 & $47,123,725$ & $47,128,375$ \\
\hline PTGIS & Prostaglandin 12 synthase & 20 & $48,120,411$ & $48,184,683$ \\
\hline TACR2 & Tachykinin receptor 2 & 10 & $71,163,659$ & $71,176,623$ \\
\hline XPNPEP1 & Aminopeptidase P1 & 10 & $111,624,524$ & $111,683,311$ \\
\hline
\end{tabular}


Table 2. Baseline characteristics of cases of angiotensin-converting enzyme inhibitor-induced cough.

Variables

Age at onset (mean [range]), years

Gender ( $[\%])$ :

- Female

- Male

$\mathrm{BMI}$ at onset (mean [range])

Smokers (n [\%])

Disease history (n [\%]):

- Hypertension

- Diabetes

- Asthma

- COPD/emphysema

- Heart failure

Type of ACE inhibitor ( $n[\%]$ ):

- C09AA02 enalapril

- C09AA05 ramipril

- C09AA06 quinapril

- C09AA03 lisinopril

Ethnicity (n [\%]):

- Swedish

- Other Nordic origin

- Swedish + other Nordic origin

- Other European origin

- Middle-Eastern origin

Concomitant medications ${ }^{\dagger}(\mathrm{n}[\%])$ :

- Drugs for obstructive airway diseases:

- R03AC B2 adrenergic agonists 17

- R03BA glucocorticoids $\quad 12$

- R03BB anticholinergics 3

- R03CA adrenoceptor agonists 2

- R03DC leukotriene receptor antagonists 1

- Number of patients taking any of the above 16 (12.9)

- Calcium channel blockers:

- C08CA dihydropyridine derivatives 16

- C08DA phenylalkylamine derivative $\quad 1$

- C08DB benzothiazepine derivatives 2

- Number of patients taking any of the above 18 (14.5)

- Diuretics:

- C03AA thiazides $\quad 25$

- C03CA loop diuretics

${ }^{+}$Only concomitant treatment with drugs for obstructive airway diseases (ATC: R03), calcium channel blockers (ATC: C08), diuretics

(ATC: C03) and beta blockers (ATC: C07) were included in the table.

ACE: Angiotensin-converting enzyme. 


\begin{tabular}{|c|c|}
\hline Variables & Cases $(n=124)$ \\
\hline \multicolumn{2}{|l|}{ - Diuretics (cont.): } \\
\hline - C03D potassium sparing agents & 6 \\
\hline - Number of patients taking any of the above & $30(24.2)$ \\
\hline \multicolumn{2}{|l|}{ - Beta blockers: } \\
\hline - C07AA05 propranolol & 3 \\
\hline - C07AB02 metoprolol & 32 \\
\hline - C07AB03 atenolol & 5 \\
\hline - C07AB07 bisoprolol & 5 \\
\hline - Number of patients taking any of the above & $43(34.7)$ \\
\hline \multicolumn{2}{|c|}{$\begin{array}{l}\text { 'Only concomitant treatment with drugs for obstructive airway diseases (ATC: R03), calcium channel blockers (ATC: C08), diuretics } \\
\text { (ATC: C03) and beta blockers (ATC: C07) were included in the table. } \\
\text { ACE: Angiotensin-converting enzyme. }\end{array}$} \\
\hline
\end{tabular}

were genotyped on an array that contained more SNPs than that used for the controls. Only 596,010 SNPs that were available on both arrays after quality control were utilized in the imputation. The 1.9 million discarded SNPs were used to check imputation quality by

\section{Table 3. Baseline characteristics of angiotensin-converting} enzyme inhibitor-treated controls.

\begin{tabular}{|c|c|}
\hline Variables & Controls $(n=1345)$ \\
\hline Age at onset (mean [range]), years & $68.9(49-96)$ \\
\hline \multicolumn{2}{|l|}{ Gender (n [\%]): } \\
\hline - Female & $481(35.8)$ \\
\hline - Male & $864(64.2)$ \\
\hline \multicolumn{2}{|l|}{ Disease history $^{\dagger}(\mathrm{n}[\%])$ : } \\
\hline - Hypertension & $668(69.9)$ \\
\hline - Diabetes & $230(24.1)$ \\
\hline - Heart failure & $162(16.9)$ \\
\hline - COPD/emphysema & $55(5.8)$ \\
\hline - Asthma & $31(3.2)$ \\
\hline - Unknown & 389 (28.9) \\
\hline \multicolumn{2}{|l|}{ Type of ACE inhibitor ${ }^{\ddagger}$ (n [\%]): } \\
\hline - C09AA02 enalapril & $1055(78.4)$ \\
\hline - C09AA05 ramipril & $239(17.8)$ \\
\hline - C09AA03 lisinopril & $27(2.0)$ \\
\hline - C09AA01 captopril & $13(1.0)$ \\
\hline - C09AA08 cilazapril & $8(0.6)$ \\
\hline - C09AA06 quinapril & $1(0.1)$ \\
\hline - C09AA09 fosinopril & $1(0.1)$ \\
\hline - C09AA10 trandolapril & $1(0.1)$ \\
\hline
\end{tabular}

comparing imputed SNPs with directly typed SNPs in the cases, when available.

Phasing and imputation were performed using the Michigan Imputation Server with the Eagle and Minimac3 pipeline and the Haplotype Reference Consortium panel as reference [19-21]. Post imputation, variants with Minimac3 R-squared value $<0.3$ were filtered out, and the data were converted to hardcall PLINK format using PLINK with QC criteria of $0.5 \% \mathrm{MAF}$, maximum $5 \%$ missing per individual and maximum $10 \%$ missing per SNP. The final dataset contained 8.6 million SNPs. In order to account for possible population stratification, principal component analysis (PCA) was performed on the nonimputed data (Supplementary Figure 2). Four genetic outliers were detected using PCA, and half of them were cases (Supplementary Figures 2 \& 3). The outliers were not excluded from the data.

All genome-wide analyses were adjusted for sex and the first four genetic principal components from the PCA. SNP effects were modeled as additive. The conventional genome-wide significance threshold $\mathrm{p}<5 \times 10^{-8}$ was used to correct for multiple testing [22]. Genome-wide analyses were performed using PLINK v1.9 and individual SNP analyses were performed using R 3.2.2 (R Foundation for Statistical Computing, Vienna, Austria).

\section{Candidate gene analysis}

Our dataset was used to replicate selected genes that had previously been associated with a risk to develop cough from ACE inhibitors (Table 1). In total 11,510 variants were available from or within $10 \mathrm{~kb}$ of the candidate genes. The significance threshold for the candidate genes was set to the Bonferroni limit of $0.05 / 11,510=4.3 \times 10^{-6}$. 


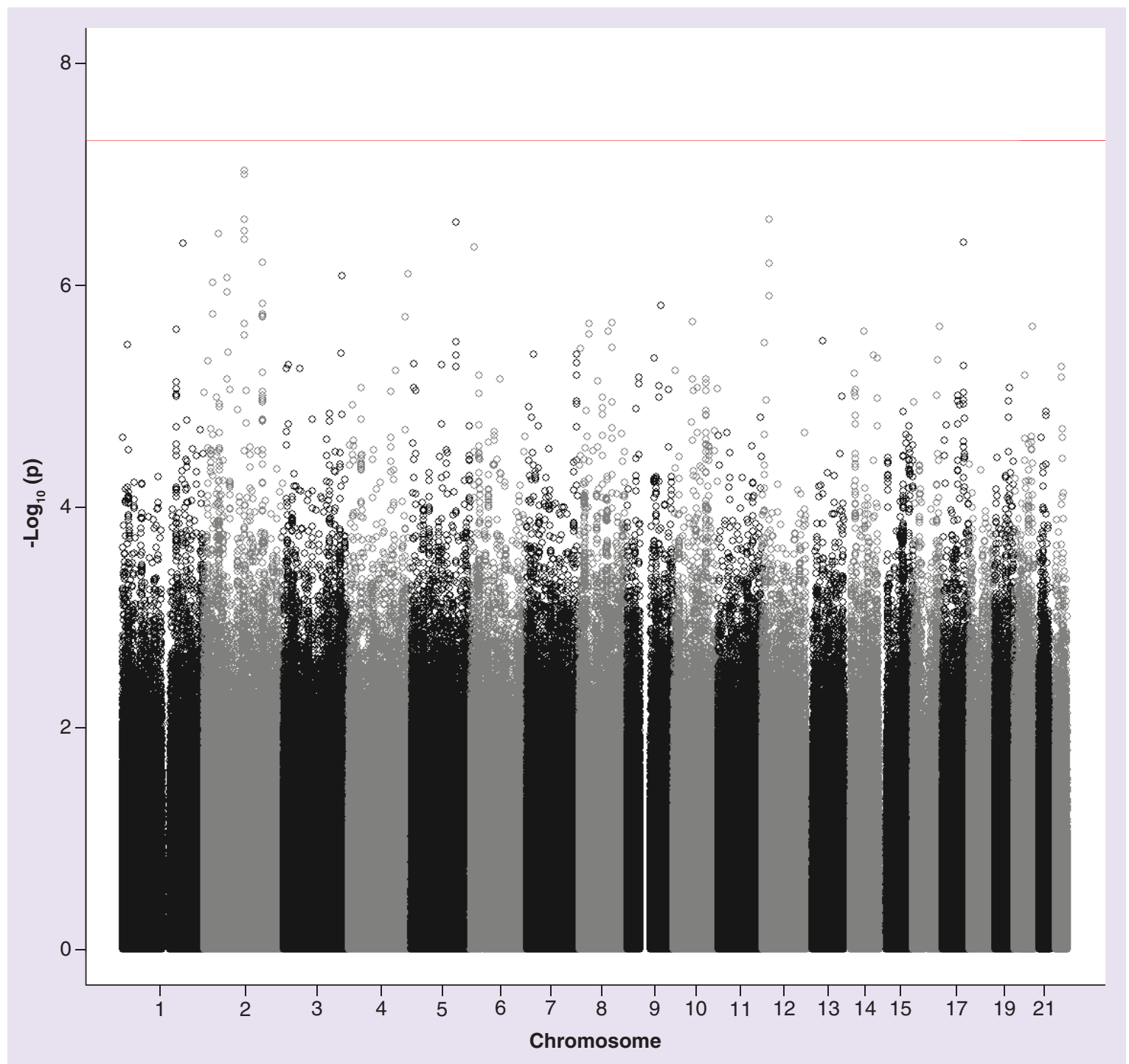

Figure 1. Genome-wide association study of angiotensin-converting enzyme inhibitor-induced cough, performed on imputed data.

\section{Results}

Baseline characteristics \& outcomes

Baseline characteristics for cases and controls are shown in Tables 2 \& 3, respectively. There was a larger percentage of females than males among cases (61 vs 39\%). A majority of the cases had Swedish origin $(87.9 \%)$. Among the cases with origins outside of Sweden, eight had ancestry from another Nordic country, four from Sweden plus another Nordic country, two from another European country and one from the Middle East. The most common ACE inhibitor used by cases was enalapril (87.9\%). A majority of the cases $(91.1 \%)$ had a disease history of hypertension, whereas $13.7,8.9,4.0$ and $0.2 \%$ had been diagnosed with diabetes, asthma, COPD/emphysema and heart failure, respectively. In addition, 12.9, 14.5, 24.2 and $34.7 \%$ of the cases had taken medications for obstructive airway diseases, calcium channel blockers, diuretics and beta blockers within 3 months before the reported ADR.

There were more males than females in the treated control group (64 vs 36\%). Among the controls with known disease history $(\mathrm{n}=956), 69.9 \%$ were diagnosed with hypertension, $24.1 \%$ with diabetes, $16.9 \%$ with heart failure, $5.8 \%$ with COPD/emphysema and $3.2 \%$ with asthma. Due to lack of disease history from a subset of controls, diagnoses were not compared between cases and controls. The most commonly used ACE inhibitors among controls were enalapril (78.4\%) and ramipril (17.8\%).

\section{Genome-wide association analyses}

Overall, there was high concordance between MAFs for imputed SNPs and directly typed SNPs in the cases (Supplementary Table 1). None of the identified 


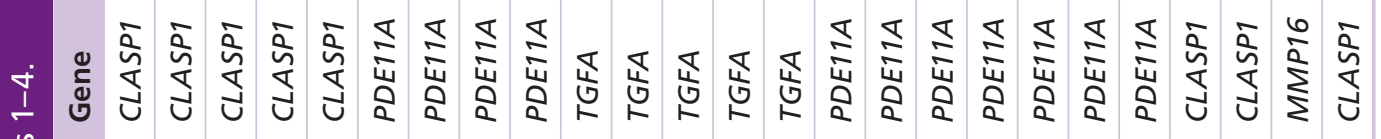

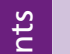

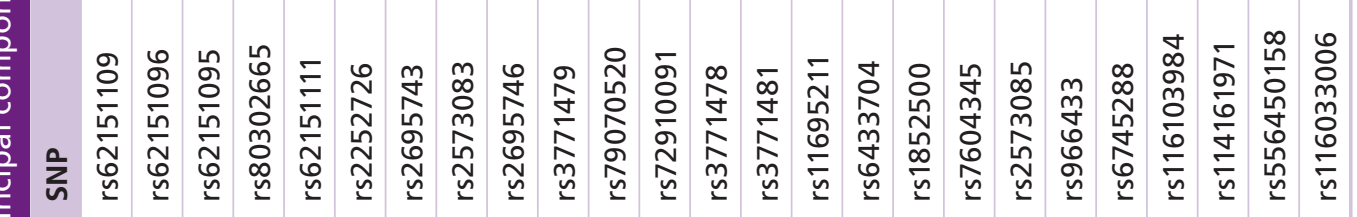
๕

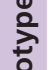

过 খ

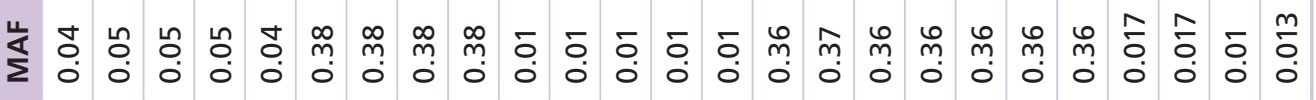

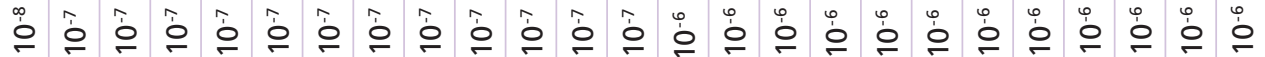

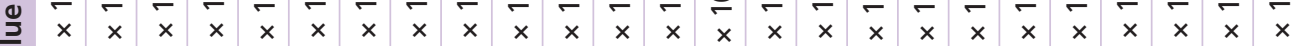

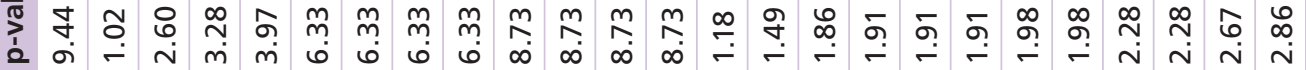

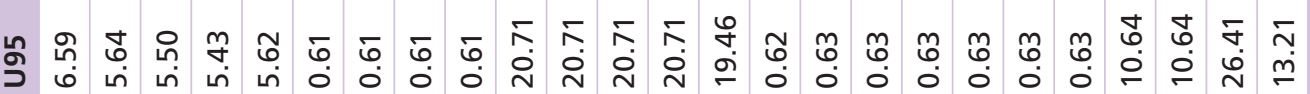

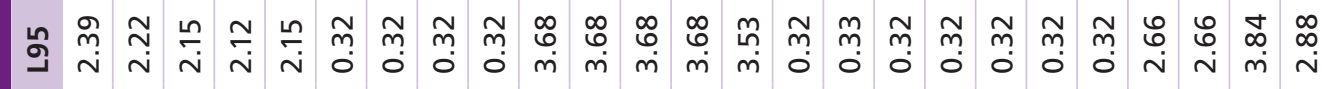

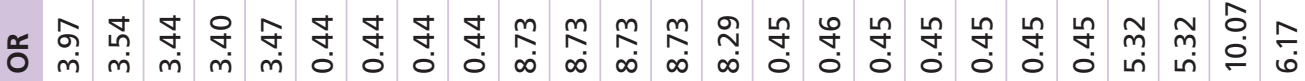

이 읻

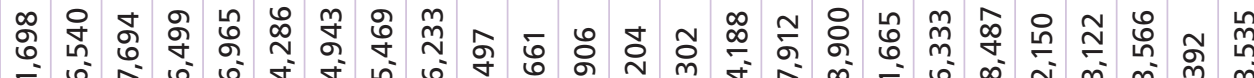

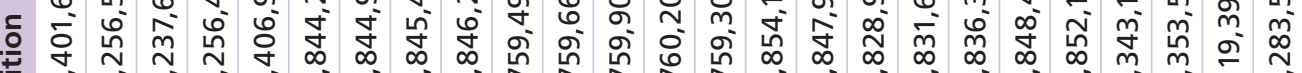

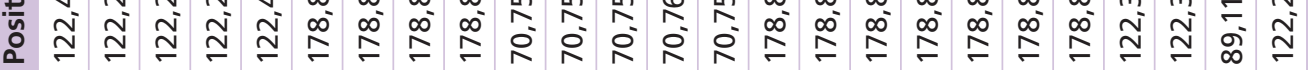


Table 5. Functions of the selected genes from the genome-wide association studies.

\begin{tabular}{|lll|}
\hline Gene & Protein & Function \\
CLASP1 & Cytoplasmic linker associated protein & Microtubule stabilization \\
\hline PDE11A & Phosphodiesterase 11A & Degradation of cAMP and cGMP in the PKA pathway \\
TGFA & Protransforming growth factor A & $\begin{array}{l}\text { Cell proliferation, mucin production, inhibition of } \\
\text { gastric acid secretion [23] }\end{array}$ \\
MMP16 & Matrix metalloproteinase 16 & Extracellular matrix remodeling \\
& & Degrades fibronectin and collagen \\
\hline Information was obtained from UniProt [24], unless otherwise stated.
\end{tabular}

SNPs passed the genome-wide significance level of $\mathrm{p}<5 \times 10^{-8}$ (Figure 1). We focused on a subset of SNPs with near significant $\mathrm{p}$-values located in genes with a possible biological association with respiratory function or cough (Tables 4 \& 5). Detailed representations of the top 60 GWAS hits with annotated gene functions are found in Supplementary Tables $2 \& 3$. The strongest association was with rs62151109 (OR: 3.97 [95\% CI: 2.39-6.59]; $\left.\mathrm{p}=9.44 \times 10^{-8}\right)$ located in an intron in CLASP1 on chromosome 2 (Table 4 \& Figure 2A). A gene of interest was PDE11A on chromosome 2 with several associated intronic SNPs: rs2252726, rs2695743, rs2573083 and rs2695746 (OR: 0.44 [95\% CI: $\left.0.32-0.61] ; \mathrm{p}=6.33 \times 10^{-7}\right)$ and $\mathrm{rs} 11695211(\mathrm{OR}:$ 0.45 [95\% CI: $0.32-0.62$ ]; $\mathrm{p}=1.49 \times 10^{-6}$ ). Other interesting intonic associations were with rs3771479, rs79070520, rs72910091, rs3771478 (OR: 8.73 [95\% CI: 3.68-20.71]; $\left.\mathrm{p}=8.73 \times 10^{-7}\right)$ and rs3771481 (OR: 8.29 [95\% CI: 3.53-19.46]; $\left.\mathrm{p}=1.18 \times 10^{-6}\right)$ located in TGFA on chromosome 2 and rs556450158 located in MMP16 on chromosome 8 (OR: 10.07 [95\% CI: 3.84-26.41]; $\left.\mathrm{p}=2.67 \times 10^{-6}\right)$ (Figure 2B-D).

\section{Functional annotation of top hits}

Study of the genomic background for the top 60 GWAS SNPs revealed that the vast majority $(58 / 60)$ was located in intronic or non-coding intergenic regions. The two SNPs reported in coding sequences were rs61733199, a missense mutation in the GYS2 gene, and rs61753726, a synonymous substitution in the VPS13B gene (Supplementary Tables 2 \& 3).

Functional annotations were obtained intersecting the top GWAS SNPs with chromatin state models based on imputed data from the Roadmap Epigenome Project [25]. We used annotations in 15 brain- and five lungderived tissues that were likely to be suitable models for the study of cough (Supplementary Tables 4-6). All CLASP1 SNPs except rs62151111 were located in intronic or intergenic regions. According to the ENCODE project, rs62151111 is located in a regulatory element in the $3^{\prime}-\mathrm{UTR}$ of CLASP1 with evidence of several transcription factors binding [26]. SNPs in
TGFA, SLC38A6 and MMP16 were located in introns, and TGFA SNPs had evidence of enhancer activity in brain and lung cells. In addition, the intronic PDE11A SNP rs11695211 was located in enhancer regions in lung fibroblasts and a lung carcinoma cell line. For more detailed information regarding the functional annotation analysis, see Supplementary Tables 4-6.

\section{Candidate gene association analyses}

None of the candidate genes associated with ACE inhibitor-induced cough in other studies (Table 1), was significantly associated with cough in our dataset (Figure 3). A detailed list of the top 60 results from the candidate gene analysis is found in Supplementary Table 7. This includes SNPs in the potassium channel gene KCNIP4 identified by Mosley and colleagues [14], although their top hit rs6838116 was not present in our dataset (Table 6 \& Figure 4). KCNIP4 isoforms are predominantly expressed in neuronal structures, and a connection between cough and neuronal activity was supported by our GWAS, although not statistically significant. Associations suggesting this were with rs115510347 in the calcium-activated potassium channel gene KCNMB2 (OR: 6.45 [95\% CI: $\left.3.07-13.53] ; \mathrm{p}=8.39 \times 10^{-7}\right)$ and with rs79755914 in the neuronal amino-acid transporter geneSLC38A6 (OR: 6.49 [95\% CI: 2.97-14.18]; $\mathrm{p}=2.66 \times 10^{-6}$ ) (Supplementary Table 2).

\section{Discussion}

The mechanism of ACE inhibitor-induced cough remains unresolved, but has been suspected to involve bradykinin [3]. Polymorphisms in the candidate gene BDKRB2 have been associated with ACE inhibitorinduced cough in some [9-12], but not in other studies [27-29]. In the present GWAS, we identified a series of genes that could be of importance for cough mechanisms independent of the bradykinin pathway. Based on our results, variations in CLASP1, TGFA and $M M P 16$ were tentatively associated with an increased cough risk (highest ORs 3.97, 8.73 and 10.07, respectively; Table 4), whereas SNPs detected in PDE11A 

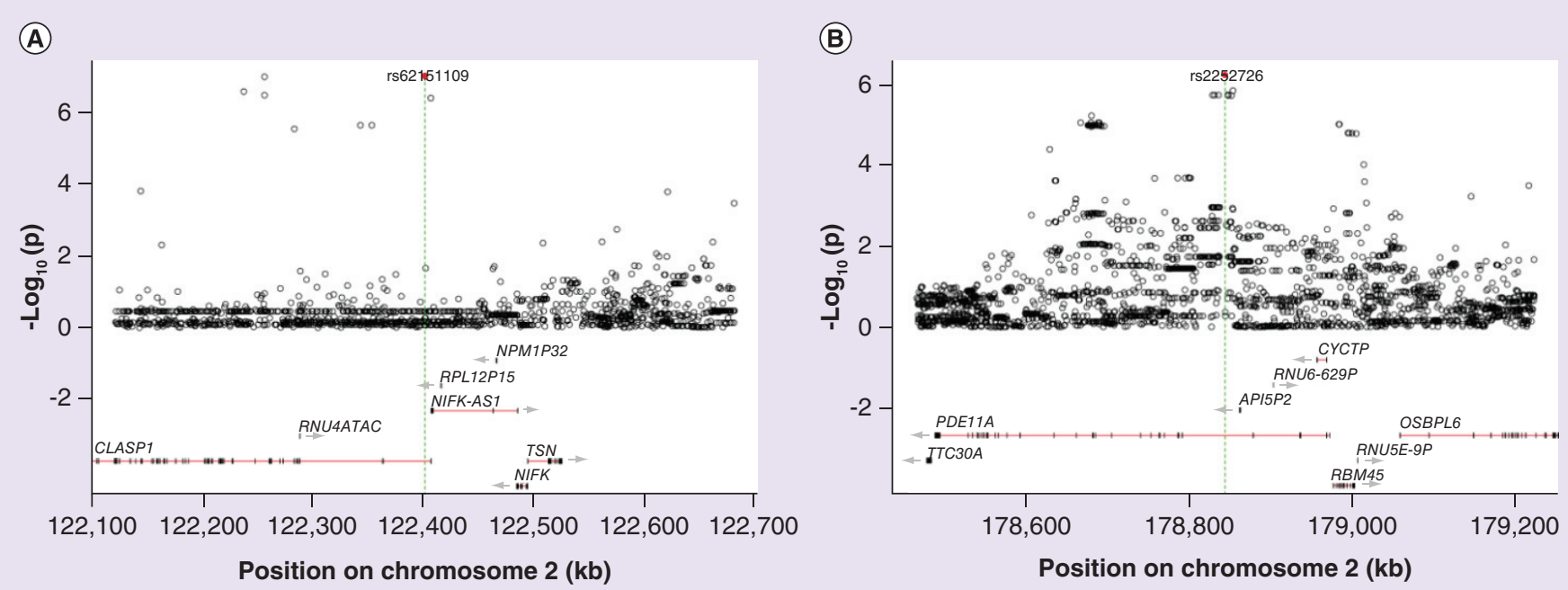

(C)
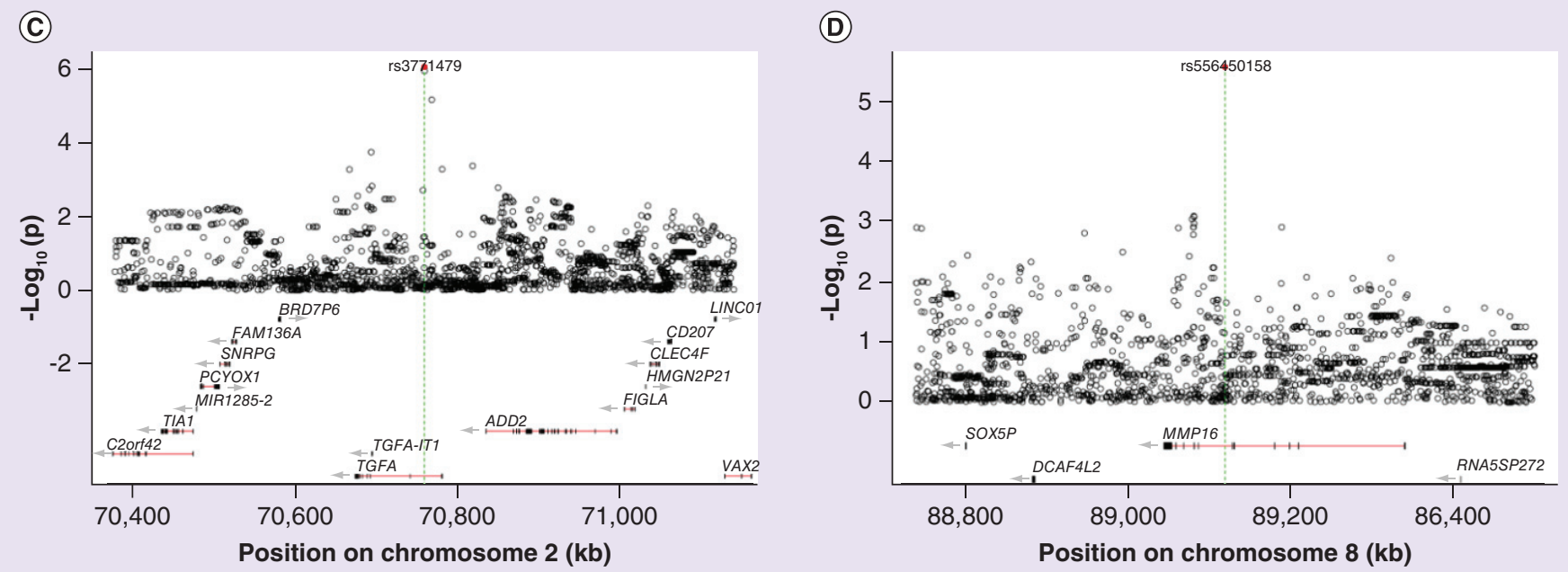

Figure 2. Regional plots of (A) the top hit rs62151109 in CLASP1, (B) rs2252726 in PDE11A, (C) rs3771479 in TGFA and (D) rs556450158 in MMP16.

protected against cough (OR: 0.44, Table 4). CLASP1, MMP16, TGFA and PDE11A are all expressed in a variety of tissues, including bronchial epithelial cells and lungs [30].

CLASP1 encodes a protein that functions as a microtubule stabilizer [31]. Microtubules are important for

\begin{tabular}{|c|c|c|c|}
\hline SNP & OR & $95 \% \mathrm{Cl}$ & p-value \\
\hline rs7661530 & 0.85 & $0.65-1.12$ & 0.25 \\
\hline rs7675300 & 0.95 & $0.73-1.25$ & 0.72 \\
\hline rs16870989 & 0.95 & $0.73-1.25$ & 0.72 \\
\hline rs145489027 & 0.95 & $0.73-1.25$ & 0.72 \\
\hline rs1495509 ${ }^{\dagger}$ & 0.95 & $0.73-1.25$ & 0.72 \\
\hline \multicolumn{4}{|c|}{$\begin{array}{l}\text { The most significantly associated SNPs in Mosley et al [14]. } \\
\text { The SNP rs6838116 is not presented, since it was not available in our dataset. } \\
\text { These SNPs were in complete linkage disequilibrium. } \\
\text { OR: Odds ratio. }\end{array}$} \\
\hline
\end{tabular}

organizing cell structures and are involved in many cellular processes, including cell division, cell migration and intracellular transport. In the respiratory tract, microtubules stabilize and coordinate the movement of microvilli in the respiratory epithelium, which is important for transporting mucus toward the pharynx. Absent or dysfunctional microvilli impair the clearance of mucus, which may trigger cough. Noscapine is an opium alkaloid without analgesic and euphoric effects that has been used as an antitussive agent to treat dry cough since the 1930s [32]. It acts as a bradykinin antagonist, but has also been shown to bind and inhibit microtubule dynamics $[33,34]$. In a study performed in patients with ACE inhibitor-induced cough, it was observed that noscapine relieved cough in $90 \%$ of the patients within 4-9 days [35]. This suggests that noscapine could have effects on both bradykinin and microtubule systems, offering the intriguing hypothesis that noscapine has a bradykinin-independent antitussive effect on ACE inhibitor-induced cough. 
TGFA is an endogenous ligand for EGFR, whose signaling pathway has been associated with regulation of mucin production in airways [23,36]. Mucins are gel-forming glycoproteins and major components in mucus that upon airway accumulation trigger a neural reflexive cough.

MMPs are involved in cell proliferation and migration and have a variety of physiological functions, including angiogenesis and degradation of extracellular matrix (ECM). In total, there are more than 20 identified MMPs, classified based on molecular structure or substrate specificity. MMP16 contains a transmembrane region, thereby belonging to a membranetype of MMP [37]. The primary ECM substrates for MMP16 are fibronectin and collagen type III [24,30]. It was previously shown that MMP12 secretion in human bronchial tissue is upregulated by inflammatory mediators, suggesting an involvement in the pathological changes seen for a variety of respiratory disorders, including asthma and COPD [38]. In a more recent study, MMP1 was suggested to affect ECM in the respiratory tract [39], as its expression was elevated in respiratory tissue from asthmatic patients compared with controls. The broad-spectrum MMP inhibitor marimastat was also observed to increase allergen tolerability in allergy-induced asthmatic patients [40]. Taken together, these studies all support an involvement of MMPs in respiratory function.

PDEs degrade intracellular cAMP to 5'AMP, which in turn decreases enzyme activity of PKA. In contrast, PDE inhibition leads to maintained cAMP levels and enhanced PKA activity, which is associated with

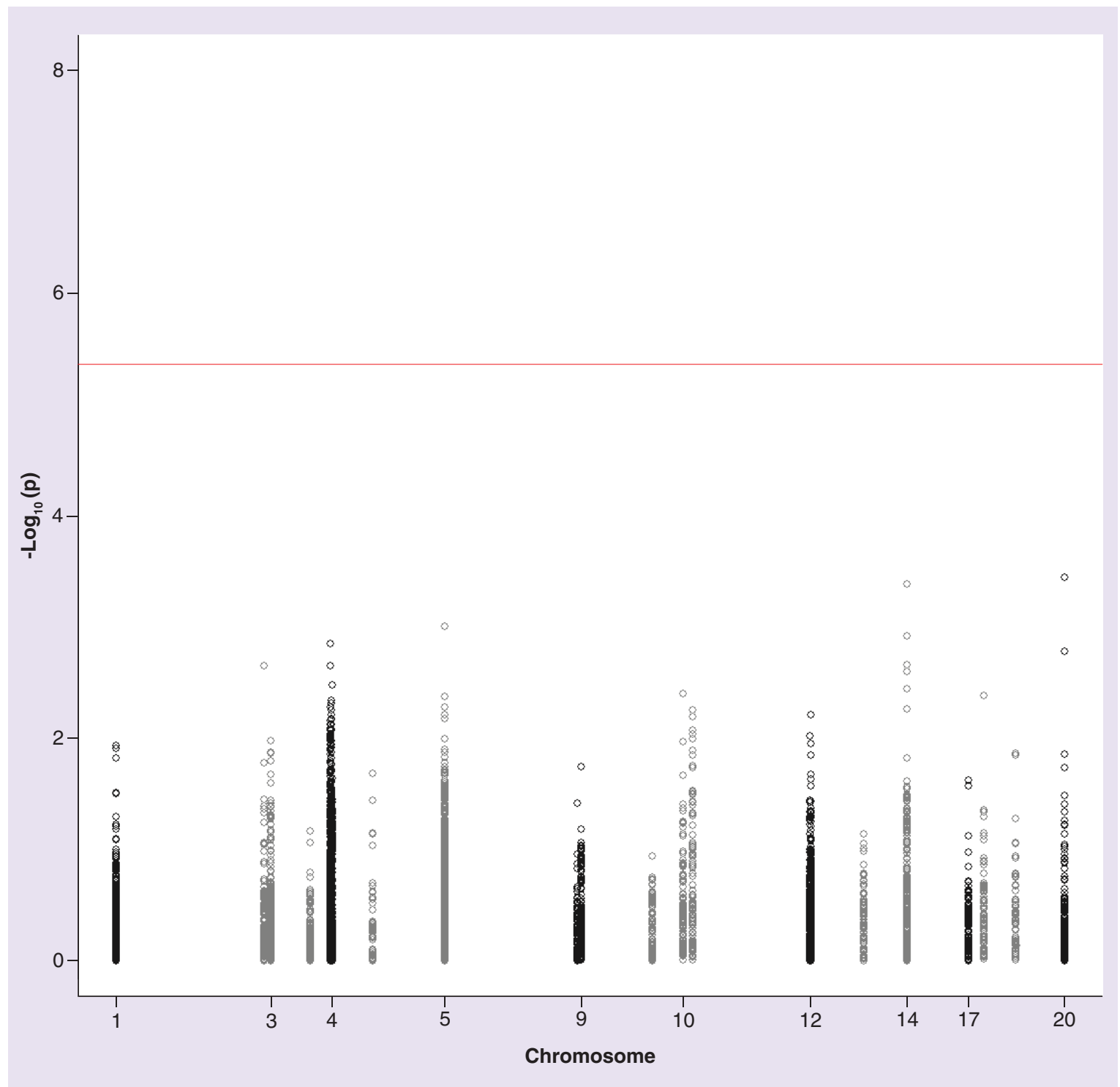

Figure 3. Candidate gene analysis of angiotensin-converting enzyme inhibitor-induced cough, performed on imputed data. 


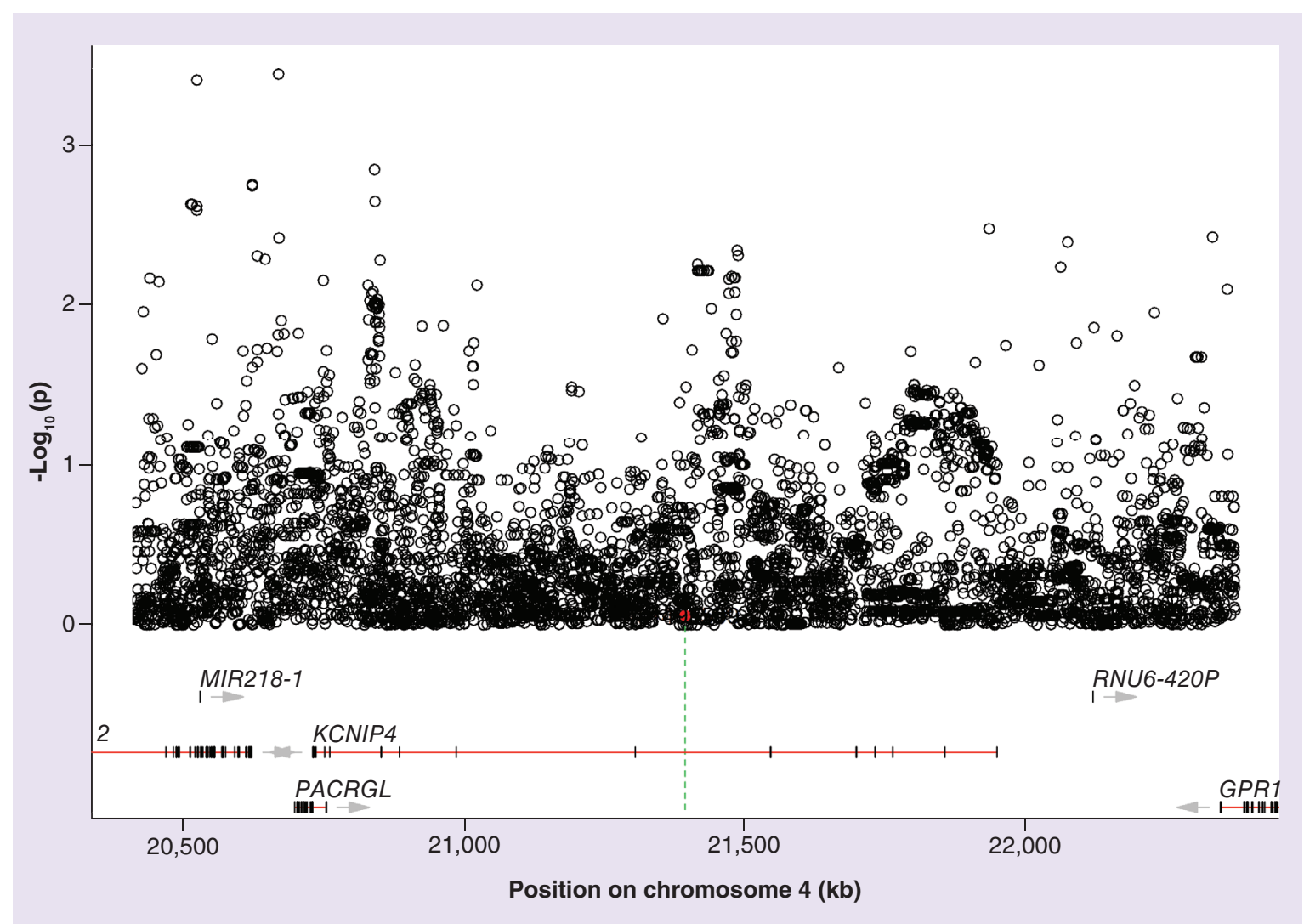

Figure 4. Region plot of KCNIP4. The green line and the red dot indicate rs1495509, which was significantly associated with angiotensin-converting enzyme inhibitor cough in Mosley et al. [14].

reduced bronchoconstriction, airway inflammation and emphysema [41]. As a consequence, a number of PDE inhibitors have been tested for treatment of respiratory disorders. For instance, the selective PDE4 inhibitor roflumilast was approved in 2010 to manage COPD, with an ability to reduce inflammation and improve forced expiratory volume [42,43]. Low-dose papaverine, which is a combined PDE4 and PDE10 inhibitor, was also reported to reduce cough induced by enalapril in guinea pigs [44]. In a GWAS performed in children suffering from allergy-induced asthma, DeWan and colleagues further found association with genetic variation in $P D E 11 A$, although no findings were genome-wide significant after correction for multiple testing [45]. The SNP rs2573088 identified in that study is located close to rs2573083 and rs2573085 that were associated with cough in our study (Table 4), which supports an association between $P D E 11 A$ and respiratory disorders.

Female gender has previously been identified as a risk factor for ACE inhibitor-induced dry cough, and this was consistent with the gender distribution in our cases. None of the candidate genes identified in previous studies showed genome-wide significance when replicated in our dataset. Although genetic variations affecting the bradykinin pathway seem to explain the risk for ACE inhibitor-induced cough in some individuals, it cannot be used to predict cough risk in most patients. Therefore, our study clearly underlines the importance of replicating studies to ensure true positive associations between genetic variants and ADRs.

\section{Limitations of the study}

The study has some limitations that deserve attention. First, it was performed in a limited number of cases, which could have caused the lack of genome-wide significant hits, although we detected some SNPs that were close to the significance level. Second, as the ACE inhibitor dose is commonly titrated at treatment initiation it was not possible to obtain the exact dose at which the ADR occurred in individual patients. Third, treated controls were eligible for the study if they had received two or more prescriptions of ACE inhibitors, based on the assumption that patients returning to the pharmacy for a second prescription of the same medication are less likely to have experienced any significant negative effects. This might however have biased our study, as cough as an ADR is easily mistaken and underreported. In addition, the results obtained here have not yet been replicated and further studies are 
needed to ensure their validity. A strength of the study is that the high imputation quality indicates that the results obtained from the GWAS are reliable. However, larger sample sizes are required to confirm the association between the novel genes found in our study and ACE inhibitor-induced cough.

\section{Conclusion}

In this GWAS, near significant associations between ACE inhibitor-induced cough and genes outside the bradykinin pathway were detected. A relationship with the potassium channel gene KCNIP4 was not confirmed, but there was a tentative association with another potassium channel gene, KCNMB2. Further, there were interesting associations with putative regulatory elements in the genes CLASP1, PDE11A and $T G F A$, all of which have been implicated in airway function. These novel findings may increase the understanding of mechanisms behind ACE inhibitor-induced cough.

\section{Future perspective}

Overall, the clinical benefit of genotyping variants that predict the risk of ADRs is estimated to be greater than that of genotyping variants that increase the risk of disease. The main reasons are that genetic variants associated with pharmacogenomic phenotypes in gen- eral have larger effect sizes than variants associated with complex disease risk, and it is easier to select an alternative drug for a patient than to modify his risk factors for complex disease [46]. Although the findings in our study do not merit predictive genotyping, future research will undoubtedly identify many other clinically actionable associations with drug response. It is anticipated that before long, patients will have their pharmacogenome available in the medical record at the time of drug prescription [47]. This would be vital for the prediction and prevention of serious and unnecessary adverse reactions, and be an important step toward precision medicine.

\section{Supplementary data}

To view the supplementary data that accompany this paper please visit the journal website at: www.futuremedicine.com/ doi/full/10.2217/pgs-2016-0184

\section{Acknowledgements}

The authors gratefully acknowledge the Swedegene team: H Kohnke, U Ramqvist, C Haglund, E Stjernberg, S Collin, E Prado Lopez, H Melhus, A Kataja Knight, ML Wadelius and A Wadelius (Department of Medical Sciences, Clinical Pharmacology, Uppsala University, Uppsala, Sweden); E Eliasson, (Karolinska Institutet, Stockholm, Sweden); I Öhman (Medical Products Agency, Uppsala, Sweden).

\section{Executive summary}

\section{Background}

- Dry cough is the most common adverse drug reaction (ADR) of angiotensin-converting enzyme (ACE) inhibitors and affects $5-35 \%$ of the patients.

- Female sex and respiratory disorders (asthma and chronic obstructive pulmonary disease) are known risk factors.

- The mechanism behind ACE inhibitor cough has been suspected to involve genetic variations in the bradykinin pathway, for example in BDKRB2, MME, PTGER and NK2R.

Patients \& methods

- A genome-wide association study was performed to identify SNP variations associated with ACE inhibitor-induced cough.

- A total of 124 cases and 1345 treated controls were included in the study and genotyped using Illumina arrays. Results

- Nearly genome-wide significant SNPs were detected in noncoding regions of CLASP1, PDE11A, TGFA, MMP16, KCNMB2 and SLC38A6.

- The top hit was rs62151109 in CLASP1 (OR: 3.97 [95\% Cl: 2.39-6.59]; $\mathrm{p}=9.44 \times 10^{-8}$ ).

- rs62151111 in CLASP1 was located in a regulatory element and rs11695211 in PDE11A in an enhancer region.

- None of the candidate genes was associated with cough in our dataset.

Discussion

- Variations in CLASP1, TGFA and MMP16 were associated with increased cough risk, whereas variations in PDE11A reduced the risk.

- CLASP1 and TGFA may be important for cilia movement and mucin production for adequate airway function and mutations in these genes could possibly trigger cough.

- Mutations in MMP and PDE genes have been implicated in respiratory airway disorders, such as asthma and chronic obstructive pulmonary disease.

- ACE inhibitor-induced cough might be partly explained by variation in genes other than those associated with the bradykinin pathway. 
Financial \& competing interests disclosure

This research was supported by the Swedish Research Council (Medicine 521-2011-2440 and 521-2014-3370), Swedish Heart and Lung Foundation (20120557 and 20140291), the Medical Products Agency, Selander's Foundation, Thureus' Foundation, Clinical Research Support (Avtal om Läkarutbildning och Forskning) at Uppsala University. T Axelsson has received grants from the Swedish Research Council, Science for Life laboratory and Uppsala University. The computations were done on resources provided by Swedish National Infrastructure for Computing through the Uppsala Multidisciplinary Center for Advanced Computational Science (UPPMAX). The authors have no relevant affiliations or financial involvement with any organization or entity with a financial interest in or financial conflict with the subject matter or materials discussed in the manuscript. This includes employment, consultancies, honoraria, stock ownership or options,

\section{References}

1 Weir MR, Henrich WL. Theoretical basis and clinical evidence for differential effects of angiotensin-converting enzyme inhibitors and angiotensin II receptor subtype 1 blockers. Curr. Opin. Nephrol. Hypertens. 9(4), 403-411 (2000).

2 The National Board of Health and Welfare, the Swedish Prescribed Drug Register. (2015). www.socialstyrelsen.se/tatistik/statistikdatabas/lakemedel

3 Dicpinigaitis PV. Angiotensin-converting enzyme inhibitorinduced cough: ACCP evidence-based clinical practice guidelines. Chest 129(Suppl. 1), S169-S173 (2006).

4 Wyskida K, Jura-Szoltys E, Smertka M, Owczarek A, Chudek J. Factors that favor the occurrence of cough in patients treated with ramipril: a pharmacoepidemiological study. Med. Sci. Monit. 18(9), PI21-PI28 (2012).

5 Morimoto T, Gandhi TK, Fiskio JM et al. An evaluation of risk factors for adverse drug events associated with angiotensinconverting enzyme inhibitors. J. Eval. Clin. Pract. 10(4), 499-509 (2004).

6 Israili $\mathrm{ZH}$, Hall WD. Cough and angioneurotic edema associated with angiotensin-converting enzyme inhibitor therapy: a review of the literature and pathophysiology. Ann. Intern. Med. 117(3), 234-242 (1992).

7 Powers BJ, Coeytaux RR, Dolor RJ et al. Updated report on comparative effectiveness of ACE inhibitors, ARBs, and direct renin inhibitors for patients with essential hypertension: much more data, little new information. J. Gen. Intern. Med. 27(6), 716-729 (2012).

8 Fox AJ, Lalloo UG, Belvisi MG, Bernareggi M, Chung KF, Barnes PJ. Bradykinin-evoked sensitization of airway sensory nerves: a mechanism for ACE-inhibitor cough. Nat. Med. 2(7), 814-817 (1996).

9 Mukae S, Itoh S, Aoki S et al. Association of polymorphisms of the renin-angiotensin system and bradykinin B2 receptor with ACE-inhibitor-related cough. J. Hum. Hypertens. 16(12), 857-863 (2002).

10 Mukae S, Aoki S, Itoh S, Iwata T, Ueda H, Katagiri T. Bradykinin $\mathrm{B}(2)$ receptor gene polymorphism is associated expert testimony, grants or patents received or pending, or royalties.

No writing assistance was utilized in the production of this manuscript.

\section{Ethical statement}

The study was approved by regional ethics committees (Uppsala Dnr 2008/213 and 2010/231 for recruitment of cases, and Stockholm Dnr 2007-644-31 and 2011/463-32 for recruitment of controls). Research was carried out in accordance with the Declaration of Helsinki. Written informed consent was obtained from all participating patients and controls.

\section{Open access}

This work is licensed under the Attribution-NonCommercialNoDerivatives 4.0 Unported License. To view a copy of this license, visit http://creativecommons.org/licenses/by-nc-nd/4.0/

with angiotensin-converting enzyme inhibitor-related cough. Hypertension 36(1), 127-131 (2000).

11 Mas S, Gasso P, Alvarez S et al. Pharmacogenetic predictors of angiotensin-converting enzyme inhibitor-induced cough: the role of $A C E, A B O$, and BDKRB2 genes. Pharmacogenet. Genomics 21(9), 531-538 (2011).

12 Grilo A, Saez-Rosas MP, Santos-Morano J et al. Identification of genetic factors associated with susceptibility to angiotensin-converting enzyme inhibitors-induced cough. Pharmacogenet. Genomics 21(1), 10-17 (2011).

13 Kim TB, Oh SY, Park HK et al. Polymorphisms in the neurokinin-2 receptor gene are associated with angiotensinconverting enzyme inhibitor-induced cough. J. Clin. Pharm. Ther. 34(4), 457-464 (2009).

14 Mosley JD, Shaffer CM, Van Driest SL et al. A genome-wide association study identifies variants in KCNIP4 associated with ACE inhibitor-induced cough. Pharmacogenomics J. 16(3), 231-237 (2016).

15 SWEDEGENE. www.swedegene.se

16 Hallberg P, Nagy J, Karawajczyk M et al. Comparison of clinical factors between patients with angiotensin-converting enzyme inhibitor-induced angioedema and cough. Ann. Pharmacother. doi:10.1177/1060028016682251 (2016) (Epub ahead of print).

17 Magnusson PK, Almqvist C, Rahman I et al. The Swedish Twin Registry: establishment of a biobank and other recent developments. Twin Res. Hum. Genet. 16(1), 317-329 (2013).

18 Purcell S, Cherny SS, Sham PC. Genetic Power Calculator: design of linkage and association genetic mapping studies of complex traits. Bioinformatics 19(1), 149-150 (2003).

19 Das S, Forer L, Schönherr S, et al. Next-generation genotype imputation service and methods. Nat. Genet. 48, 1284-1287 (2016).

20 Loh P, Danecek P, Palamara PF, et al. Reference-based phasing using the Haplotype Reference Consortium panel. (2016). Nat. Genet. 48(11), 1443-1448 (2016). 
21 McCarthy S, Das S, Kretzschmar W, et al. A reference panel of 64,976 haplotypes for genotype imputation. Nat. Genet. 48, 1279-1283 (2016).

Sham PC, Purcell SM. Statistical power and significance testing in large-scale genetic studies. Nat. Rev. Genet. 15(5), 335-346 (2014).

23 Takeyama K, Dabbagh K, Lee HM et al. Epidermal growth factor system regulates mucin production in airways. Proc. Natl Acad. Sci. USA 96(6), 3081-3086 (1999).

Uniprot C. UniProt: a hub for protein information. Nucleic Acids Res. 43, D204-D212 (2015).

Roadmap Epigenomics Consortium, Kundaje A, Meuleman W et al. Integrative analysis of 111 reference human epigenomes. Nature 518(7539), 317-330 (2015).

Consortium. An integrated encyclopedia of DNA elements in the human genome. Nature 489(7414), 57-74 (2012).

27 Nishio K, Kashiki S, Tachibana H, Kobayashi Y. Angiotensin-converting enzyme and bradykinin gene polymorphisms and cough: a meta-analysis. World J. Cardiol. 3(10), 329-336 (2011).

28 Zee RY, Rao VS, Paster RZ, Sweet CS, Lindpaintner K. Three candidate genes and angiotensin-converting enzyme inhibitor-related cough: a pharmacogenetic analysis. Hypertension 31(4), 925-928 (1998).

29 Woo SW, Bang S, Chung MW, Jin SK, Kim YS, Lee SH. Lack of association between $\mathrm{ACE}$ and bradykinin $\mathrm{B} 2$ receptor gene polymorphisms and ACE inhibitor-induced coughing in hypertensive Koreans. J. Clin. Pharm. Ther. 34(5), 561-567 (2009).

30 Uhlen M, Fagerberg L, Hallstrom BM et al. Proteomics. Tissue-based map of the human proteome. Science 347(6220), 1260419 (2015).

31 Akhmanova A, Hoogenraad CC, Drabek K et al. Clasps are CLIP-115 and -170 associating proteins involved in the regional regulation of microtubule dynamics in motile fibroblasts. Cell 104(6), 923-935 (2001).

32 Rida PC, Livecche D, Ogden A, Zhou J, Aneja R. The Noscapine Chronicle: a pharmaco-historic biography of the opiate alkaloid family and its clinical applications. Med. Res. Rev. 35(5), 1072-1096 (2015).

33 Mahmoudian M, Mojaverian N. Efffect of noscapine, the antitussive opioid alkaloid, on bradykinin-induced smooth muscle contraction in the isolated ileum of the guinea-pig. Acta Physiol. Hung. 88(3-4), 231-237 (2001). antitumor agent that arrests metaphase and induces apoptosis

in dividing cells. Proc. Natl Acad. Sci. USA 95(4), 1601-1606 (1998).

35 Mooraki A, Jenabi A, Jabbari M et al. Noscapine suppresses angiotensin converting enzyme inhibitors-induced cough. Nephrology (Carlton) 10(4), 348-350 (2005).

36 Singh B, Coffey RJ. From wavy hair to naked proteins: the role of transforming growth factor alpha in health and disease. Semin. Cell Dev. Biol. 28, 12-21 (2014).

37 Vu TH, Werb Z. Matrix metalloproteinases: effectors of development and normal physiology. Genes Dev. 14(17), 2123-2133 (2000).

38 Xie S, Issa R, Sukkar MB et al. Induction and regulation of matrix metalloproteinase-12 in human airway smooth muscle cells. Respir. Res. 6, 148 (2005).

39 Rogers NK, Clements D, Dongre A, Harrison TW, Shaw D, Johnson SR. Extra-cellular matrix proteins induce matrix metalloproteinase-1 (MMP-1) activity and increase airway smooth muscle contraction in asthma. PLoS ONE 9(2), e90565 (2014).

40 Bruce C, Thomas PS. The effect of marimastat, a metalloprotease inhibitor, on allergen-induced asthmatic hyper-reactivity. Toxicol. Appl. Pharmacol. 205(2), 126-132 (2005).

41 Bender AT, Beavo JA. Cyclic nucleotide phosphodiesterases: molecular regulation to clinical use. Pharmacol. Rev. 58(3), 488-520 (2006).

42 Rabe KF, Bateman ED, O'Donnell D, Witte S, Bredenbroker D, Bethke TD. Roflumilast-an oral antiinflammatory treatment for chronic obstructive pulmonary disease: a randomised controlled trial. Lancet 366(9485), 563-571 (2005).

43 Garnock-Jones KP. Roflumilast: a review in COPD. Drugs 75(14), 1645-1656 (2015).

44 Ebrahimi SA, Saghaeian-Shahri T, Shafiei M, Rostami P, Mahmoudian M. Interaction of papaverine with the enalapril-induced cough in guinea pig. Acta Physiol. Hung. 93(1), 71-78 (2006).

45 Dewan AT, Triche EW, Xu X et al. PDE11A associations with asthma: results of a genome-wide association scan. J. Allergy Clin. Immunol. 126(4), 871e879-873e879 (2010).

46 Maranville JC, Cox NJ. Pharmacogenomic variants have larger effect sizes than genetic variants associated with other dichotomous complex traits. Pharmacogenomics J. 16(4), 388-392 (2016).

47 Relling MV, Evans WE. Pharmacogenomics in the clinic. Nature 526(7573), 343-350 (2015). 